Session 2003-1892

\title{
Evolving Models of Curricular Change: The Experience of the Foundation Coalition
}

\author{
M. Carolyn Clark, Jeff Froyd, Prudence Merton, and Jim Richardson \\ Texas A\&M University / Texas A\&M University/ Texas A\&M University/ University of \\ Alabama
}

\begin{abstract}
This paper examines one aspect of the curricular change process undertaken by the Foundation Coalition, namely how the understandings about change held by the FC leaders evolved as they moved through the process of developing and implementing a new curriculum. We show how those change models became more complex as they struggled with three major issues: the role of assessment data, the limitations of the pilot for gaining full-scale adoption of the new curriculum, and the need for structural change to sustain the new curriculum.
\end{abstract}

\section{Introduction}

One of the more recent initiatives in improving undergraduate engineering education has been conducted by the NSF sponsored Foundation Coalition (FC), a partnership between six institutions that, starting in 1993, designed, implemented, and institutionalized innovative freshman and, in some cases, sophomore curricula. In this paper we focus on the FC's evolving model of the curricular change process. Using examples from different partner institutions we will illustrate how three underlying assumptions about change held by FC leadership proved problematic at different stages of the change process. One assumption is that positive assessment data is sufficient to persuade the rest of the college that the curriculum should be adopted. A second assumption is that the information resulting from the pilot is sufficient in deciding how the curriculum can be improved for all students. And finally, there is an assumption that once the new curriculum is institutionalized, the job of effecting "systemic reform of undergraduate engineering education" is complete. This paper is one product from a qualitative study of the FC curricular change process.

\section{Introduction}

Since the earliest formal review of engineering education during the first International Congress of Engineering in Chicago in 1893 [1], engineers, engineering educators, and representatives from industry and government have been assessing every 20 years or so how well our educational institutions prepare engineers for current social needs. This periodic process of self-investigation, reflection and recommended curricular revision has led one British observer to proclaim American 
engineering education as "the most visible undergraduate curriculum in the United States... and the subject of persistent experiment."'[2]

One of the more recent initiatives in improving undergraduate engineering education has been conducted by the NSF-sponsored Foundation Coalition (FC), currently consisting of six institutions: Arizona State University (ASU), Rose-Hulman Institute of Technology (RHIT), Texas A\&M University (TAMU), the University of Alabama (UA), the University of Massachusetts at Dartmouth (UMD), and the University of Wisconsin at Madison (UWM). Each partner institution worked within their particular and differing contexts to develop innovative curricula based on four thrusts: integration of conceptual concepts across disciplines; active and cooperative learning; the use of technology in the classroom; and on-going assessment and evaluation.

We conducted an extensive qualitative study of the curricular change experience within the Foundation Coalition. The story varied across the FC, both because each institution had unique sets of characteristics and because the leaders in each program chose to emphasize certain of the thrusts and de-emphasize others in order to tailor the curricula to their particular needs. Yet, while the details differed, there were also some common elements of the change process across the six institutions. Our goal in this paper is to examine how the FC leaders' conceptualization of change itself evolved as they attempted to move their innovative curricula from the pilot stage to institutionalization. We begin by first describing the methodology we used to conduct our study. Then we out line what we believe was the initial change model that guided the work of the Foundation Coalition. To track the changes in that model, we examine three issues with which the FC leaders struggled as their work progressed: the role of assessment data in getting the curriculum adopted; the limitations in using a pilot curriculum as a prelude to full-scale implementation; and finally, the complex challenge of sustaining the new curriculum. As we examine those experiences, we show how their model of change evolved. We conclude with a discussion of the implications of these sequential understandings about change for curricular development in higher education.

\section{Methodology}

The best way to study a complex experience is through the use of qualitative research. This methodology has several defining characteristics. [3, 4] Its focus, first of all, is on understanding the meaning people give to their experience. Because meaning-making is a fundamental human activity, the best way to understand it is through personal interaction, and that means that the primary instrument for collecting and making sense of qualitative data is the researcher him- or herself. It's also important that the researcher go to the people being studied so that their context can be understood, a critical element since the meaning they give to their experience is shaped in multiple ways by their context. Typically qualitative data are generated through interviews, observations, and the analysis of documents. The sample is purposive, meaning that participants are selected for the information or perspective they can give about the phenomenon under study. Qualitative research by nature is inductive, building rather than testing theory, and the knowledge it produces is highly descriptive. 
There are lots of different kinds of qualitative research; the particular mode we used to study the FC was case study research. [3] A case is any bounded system, such as a school, a business, or a community, that becomes the unit of analysis in a study. It is bounded in the sense that its definitional borders are clear. This was a multi-case study, with each FC institution forming a separate case, and for those programs that had designed both freshmen and sophomore curricula (RHIT and TAMU), separate cases were constructed for each curriculum. We completed a total of eight case studies in this research project. For each case, members of our team went to that institution and conducted individual interviews with faculty, staff, and administrators in that program. We usually interviewed between 20 to 25 people at each institution, working closely with the FC coordinator at each site to select a range of participants - faculty members who had designed and/or taught in the program; the dean, key department heads, and other relevant administrators; those who played a leadership role in the FC program itself, faculty and administrators in non-engineering departments; and engineering faculty who had not been involved with the FC but who had an informed opinion about it. We took care to include both opponents and supporters of the new curriculum. Each interview was semi-structured and lasted about an hour; all interviews were audio taped. In the interview participants were asked to tell the story, from their perspective, of the development and implementation of the new curriculum at their institution. This included describing how they got involved in the program and what role they played; what the key decision points were in the change process; what factors moved that process forward and what factors inhibited it; and what lessons they learned about curricular change from their experience.

Each interview was transcribed verbatim and those transcripts were analyzed using the constant comparative method. [3] Each interview was broken into segments and coded for its content (for example, a discussion of the promotion and tenure process was coded "reward system"; a discussion of gaining support for the program was coded "buy-in"), and these data were entered into Ethnograph, a software program designed to manage qualitative data. This enabled us to look for patterns and themes within and across these categories. What emerged was a complex picture of how each college of engineering within the FC experienced the curricular change process. For each case we drafted an initial case report and shared it with those who were interviewed, asking for their feedback. We then used that feedback to revise each case report.

Our cross-case analysis worked in a similar way, looking for themes across the entire data set. While each institution was unique, there were commonalities across the group that enabled us to draw a number of conclusions about the curricular change process. The findings in this paper draw from that cross-case analysis.

\section{The Evolving Model of Change}

The original FC action plan for the first five years (1993-1998) called for renewing the entire fouryear undergraduate engineering curriculum and incorporating the four thrusts mentioned above. During the first year of the grant, each FC institution designed a freshman pilot curriculum. In the second year, FC schools implemented the freshman pilot and simultaneously designed a pilot sophomore curriculum. The curricula for these "foundation years" were modeled on two already existing programs: the Integrated, First-year Curriculum in Science, Engineering and Mathematics 
[5] that was initiated at RHIT in 1990 and the Sophomore Core Engineering Curriculum [6-11] that was initiated at TAMU in 1989. For the 1995-96 academic year or third year of the grant, each FC partner intended to improve its first-year curriculum pilot, implement a sophomore curriculum pilot, and prepare plans for pilots of a junior curriculum in one or more engineering major(s). The action plan called for work in the fourth and fifth years of the grant to continue in a similar fashion until the entire undergraduate engineering curricula were restructured.

FC faculty and administrators approached their task with a mental model of how curricular change occurs. The term "mental model" [12] refers to the mental representations of reality that people use to understand phenomena. They contribute to people's pictures, ideas, and conceptions of how the world operates. In its simplest form, the mental model of change, prevalent at the beginning of the $\mathrm{FC}$ and reflected in the action plan, focused on developing and perfecting a pilot curriculum. It is depicted in Figure 1.

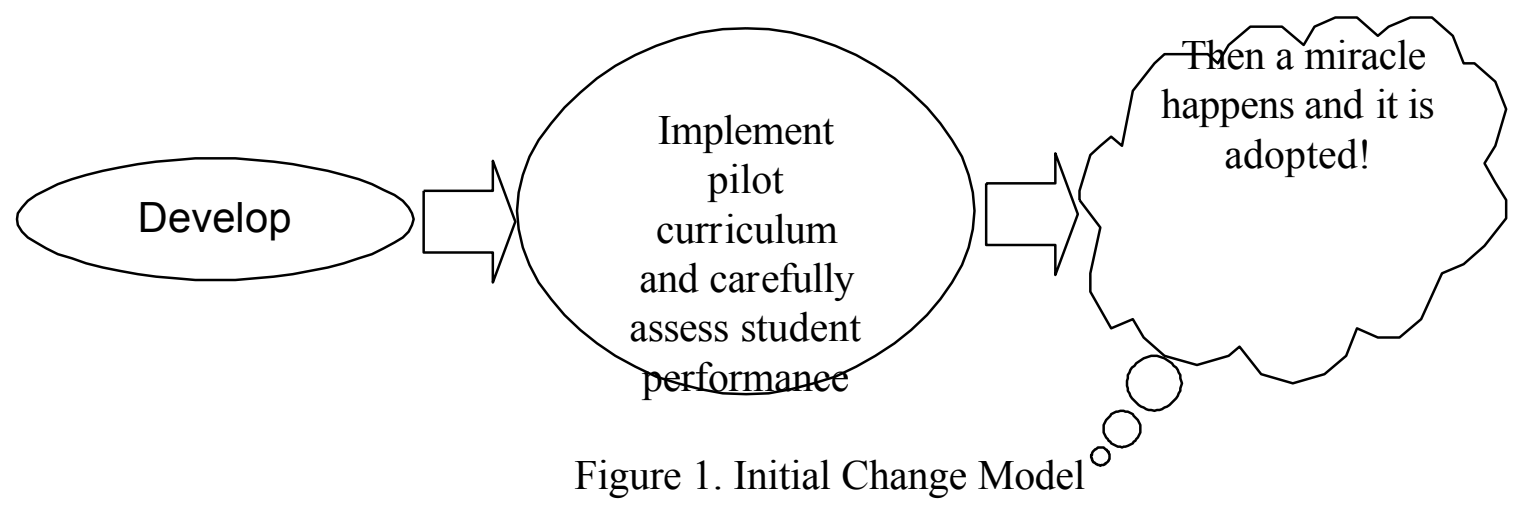

Figure 1 represents the following change process:

- Formulate and implement a curriculum pilot that incorporated the key components of the FC.

- Collect assessment data from the implementation of the curriculum pilot

- Use the hopefully positive data from the pilot to motivate adoption of the new curriculum across the entire college of engineering.

In the initial change model, the "miracle" is heavily dependent on the pilot and the resulting assessment data. There are some implicit assumptions underlying the model about how change occurs. One assumption is that positive assessment data is sufficient to persuade the rest of the college that the curriculum should be adopted. A second assumption is that the information resulting from the pilot is sufficient in deciding how the curriculum can be improved for all students. Another assumption is that experience with the pilot curriculum will provide an adequate base on which to design institutionalized versions of the pilot curriculum. And finally, there is an assumption that once the new curriculum is institutionalized, the job of effecting curricular change is complete, i.e., that maintaining and sustaining the curriculum does not require additional attention or innovative institutional structures. What we saw in our study was that the 
FC leaders learned that these assumptions were wrong and that their learning reshaped the implicit change model that they were using. We turn now to an exploration of those learning experiences and the resultant evolution of the FC change model.

\section{The Role of Assessment Data}

There is a long-standing relationship between assessment and curricular change. It makes no sense to collect evidence of student learning without making use of that information to improve or maintain courses and programs. Throughout the FC, assessment data were used to facilitate curricular decision-making. FC leaders believed if assessment data gathered during the pilot phase were positive, i.e., showing that student retention and/or learning had improved, that would be sufficient to justify expanding the pilot to accommodate the entire freshman (or sophomore) class. This belief about assessment data was especially strong at UMD, because designing the pilot, implementing the pilot, and deciding to construct a renewed first-year curriculum for all engineering majors at UMD occurred over a short period of time.

Assessment data played a highly visible role in the debate over adoption of their prototype freshman curriculum. With support from the Davis Foundation, UMD designed a pilot first-year curriculum [referred to as the Integrated Math, Physics, Undergraduate Laboratory Science, and Engineering program (IMPULSE)] in the 1997-98 academic year and offered a pilot for 48 students in fall 1998. Unlike other FC institutions, UMD piloted their program for only one semester before they proposed adoption of the program to the college. They made this choice for a number of reasons. Early data were indicating greater retention and class attendance, and students were receiving better grades when compared to other sections of similar classes. Secondly, the school was receiving good publicity about the program and interest in the program was coming in from potential students and their parents. Probably the biggest incentive for quick action, however, was the impending loss of their dean, who was a big supporter of the program. IMPULSE developers were aware of similar situations at other FC institutions where, in the absence of a permanent dean, adoption of the new curriculum was stalled, sometimes for years. They wanted to avoid this potential problem. A developer said, "We knew we were going to go from a supportive dean to no dean, basically. And in the no dean situation, nobody would take the risk...so while we had a supportive dean, maybe we had to bring it up for adoption."

With the greater reduced time frame for implementation, problems with the assessment process surfaced. While IMPULSE faculty perceived that the program was better, they discovered that doing effective assessment was more difficult than they had thought. A team member said:

I had never thought about [the difficulty of] keeping track of all that data....We quickly learned that you can ask faculty to do an assessment, and tell them what day to do it and give them the stuff several days in advance, and they won't do it, they'll forget. So somebody has to show up at the door and go in and pass it out and then take it back up and take it out and call them up every few days around finals and remind them of what they said they would do and go pick it up, and that takes time and effort and energy that we weren't prepared to do ...

Even without a formal assessment process in place, the UMD team felt the grades, increased retention and good publicity warranted scaling up the program (see [13] and [14] for examples of 
the data that was eventually presented to UMD faculty members). The developers proposed adopting IMPULSE college-wide during a college faculty meeting at the beginning of the Spring 1999 semester. Resistance from faculty was immediate and intense. Most of the rationale for the resistance focused on their perception that available assessment data did not demonstrate that the program was an improvement over the curriculum currently in place. A major criticism from the opposition was that the pilot had only the calculus-ready students, while the traditional program had mostly pre-calculus students. A senior faculty member commented, "[They] had culled out the best students we had for this."

An assessment specialist from outside the college and a faculty assessment coordinator were hired. The team members themselves felt the assessment people had no investment in a particular outcome in the adoption debate and that this would provide more credibility to the data they generated. The assessment specialist told us, "One of the things that was successful in the role that they [gave] me over here was that I didn't have a big agenda on whether they took the program or not. There were people on campus that had a strong opinion about whether the program should be adopted, [going] both ways. And both groups felt they could call this number, email here, and get more data." While there were assessment people in place, it was too early for them to have a unified, planned approach to assessing the impact of IMPULSE. The team had gathered data from other innovative programs at other schools delineating major indicators of their programs' effectiveness. The assessment team then hurriedly gathered historical data at UMD about grades, GPA's, and attrition rates.

One surprising result of this historical data was that it showed the past attrition rate for some engineering departments was as high as $70 \%$. Faculty awareness of this high attrition rate had always been somewhat hidden by a high rate of transfer of students from local community colleges. These data also showed that the students who left were some of the best, with high GPAs and SAT scores. The magnitude of the college's retention problem became more apparent. One team member shared with us how his department responded when he presented this data to them in order to ask for their support of the new curriculum:

When they started seeing the fact that we were losing students with very high SAT scores, very high overall GPAs, that were leaving engineering, they were saying, "Why?"...We started finding out that those students were going to [other institutions]. They were going to arts. They were going to physics. They were going to mathematics. They were leaving for other schools, and it was because they were frustrated. You know, I think that opened some minds...

Despite that fact that the data about IMPULSE seemed positive, it became an instrument for both defenders and attackers of the new program. One staff person described the situation as a "data war" in which some faculty members were "using the data to attack each other." A few professors essentially accused the developers of the new curriculum of "cooking" the data. A member of the team said, "There were a couple of meetings at which [the lead developer] was accused of making the numbers say the things that he wanted them to say and other people came up with their own numbers to show that things were somewhat different." A member of the assessment team noted that, in any situation, data are persuasive only for those who aren't biased.

Proceedings of the 2003 American Society for Engineering Education Annual Conference \& Exposition Copyright (C)2003, American Society for Engineering Education 
In a situation where many of the faculty already had fixed opinions, the data will not change minds.

In January 1999, the dean appointed a review committee of four senior faculty to look at the assessment data gathered so far, asking them, "Should the college expand the [new] methodology and curriculum beyond the present phase of 48 students?" The review committee was given the data that had been generated up to that point.

Proving that the program was an improvement over the traditional curriculum continued to be difficult for the promoters. The absence of an identical control group was a problem. (Of the 90odd members of the new freshman class, 48 of the 50 calculus-ready students were invited and admitted into the IMPULSE program). The review committee recommended that the program be run as a pilot for another year to gather more valid assessment data as "no definitive conclusions can be drawn regarding failure or success of" the new curriculum. They submitted their report to the dean in February. In the meantime, the assessment team continued to generate more uniform data and a report was presented to the College in March. The proponents of the new curriculum continued to fight for adoption of the program. At the end of March, the dean responded to the review committee's report and the data that had been generated subsequent to the review committee and recommended expanding the new curriculum for the following fall semester.

The developers of IMPULSE, like the developers of innovative curricula at other FC schools, concentrated on the nuts and bolts of developing the new curriculum and did not emphasize activities that would help their colleagues want to change. Developing a well-planned assessment program, with input from all constituents, is only one activity that can support change in faculty not participating in development of the new curriculum. The following comment from one administrator at another FC institution stresses how assessment can be useful:

Quantitative assessment is necessary but it won't be sufficient, and won't ever be. I mean, even if you had tested the right stuff, it wouldn't convince people. But you have to have good assessment to stay in the conversation of what we've really got to do.

University faculty members are not accustomed to basing curricular decisions on assessment data. In several instances, faculty cited either first-hand experience teaching the pilot curriculum, or the recommendation of a respected colleague who had designed or taught in the curriculum as the reason their department voted to adopt the new FC-sponsored curriculum. One FC leader commented on the experience at the University of Alabama,

When faculty could tell the difference between students who'd gone through the Coalition and students who hadn't, then even the critics said, "Hey, these guys have got something here." It wasn't the fact that somebody could put a curriculum down in front of somebody and say, "Look, this is a better curriculum," or show assessment data or anything else. It was the fact that students were demonstrably different.

In experiences similar to UMD, FC leaders at each FC institution that offered a pilot curriculum 
learned that while quality assessment is required, the decision to adopt a curriculum involves more than building a persuasive case using quantitative data. Similar experiences have been recorded elsewhere. For example, a rigorous and carefully developed assessment and evaluation plan showed that structured active learning (SAL) techniques significantly increased student learning in a freshman chemistry course at the University of Wisconsin-Madison. However, the positive results did not motivate widespread change among faculty within the department. [15, 16] Using pilots as educational experiments is problematic overall. [17]

Our study shows that assessment data gathered during the piloting of the new curriculum were necessary to engage and sustain conversations about the possibilities of adopting the curriculum for all engineering majors. However, at no FC partner institution were the assessment data alone sufficient to move the non-FC faculty to adopt a new curriculum. The initial change model that the FC leaders were using, with its emphasis on the pilot curriculum, was beginning to be problematic, but there were greater problems than the issue of assessment data. We turn now to examine some of those other issues.

\section{Limitations of Pilot Curricula as a Base for Moving to Institutionalization}

Pilot curricula, by their nature, involve a small numbers of students and faculty members. Students who participated in relatively small numbers in the pilot curricula at each FC institution were not representative of all engineering majors at that institution. Typically only calculus-ready students who did not have advanced placement (AP) credit participated in first-year curriculum pilots. However, a first-year curriculum for all engineering majors must accommodate a broad range of students - those who are not ready to enter calculus, those with significant AP credit, commuter students, part-time students, and transfer students. The restricted set of students and faculty members who were involved in the pilot curricula raised questions about the degree to which results from the pilot curricula may be generalized to the larger set of engineering majors. Scale-up meant using learning from the pilot to design an institutional system that would accommodate the breadth of student diversity. The assumption that the information resulting from the pilot is sufficient in deciding how the curriculum can be improved for all students proved to have serious limitations.

Moving from the pilot stage to full implementation is essentially moving from the ideal to the real, and the process is neither smooth nor easy. In this section we explore this issue by focusing on the experience at TAMU in implementing their FC sophomore curriculum. They actually had two pilot programs. The first one, known as $20 \mathrm{X}$ (reflecting the catalog numbers of the courses involved), was developed prior to the creation of the Foundation Coalition and was adopted as a model for FC sophomore curricula at other institutions. Designers at TAMU revised the 20X curriculum and created $21 \mathrm{X}$ to be the FC sophomore pilot, and it was this curriculum that was adopted for all engineering majors in 1997. [18]

Many of the issues TAMU faced were logistical. Their College of Engineering is the one of the largest in the country, so the size of the student body itself presented a significant challenge. The sophomore pilot involved 200 students; the entire sophomore class consisted of about 1400 students. The traditional sophomore curriculum, in which about $80 \%$ of the students were 
enrolled at that time, was eliminated within a two-year period. It also meant that the pilot curriculum itself had to be changed to accommodate the larger context. The transition meant uncertainty for everybody. One of the FC leaders called this period "a nightmare" and, given the scope, it is unimaginable that it could have been otherwise. The student advisors played a critical role in the transition. Administrative details, like making the necessary changes in the registration process, were handled by an associate dean.

One immediate issue was faculty staffing. In the pilot phase courses were taught by a select group of faculty. When the new curriculum was mainstreamed many more faculty were needed. There was already a system in place that had been used to staff the courses in the first-year curriculum, and it provided a mechanism to address this issue with the new curriculum. Known as the barter system, it involved a complex calculation, made in the associate dean's office, of how many faculty each department would provide to teach the sophomore courses, as well as other service courses, like engineering ethics. Once the determination was made, the department heads proposed specific faculty and the associate dean makes the final selection (the so-called right of first refusal). The downside, however, is that there is less control over who exactly teaches these courses.

In the pilot phase, at least early on, an apprenticeship model was used to train interested faculty-a new faculty member would teach with someone who had experience in the Coalition and was already trained in the new pedagogy. But, as one observer noted,

...that was going to be inadequate to handle the whole full blown adoption, just the numbers were going to be way too big to do that, even though there was an attempt to try to expand the membership of the club every year for that. But they lost as many as they gained, so [they] had more people trained but not everybody was willing to continue working in it. That was a hook-or-crook model, rather than a serious resource allocation. If you're going to do it seriously, it seemed to me, you needed to put resources to bear on this and say, OK, you're going to do this, we will give you a release to do it or we will count it for your load.... That seemed an administrative lapse. That was never seriously considered as a major tool to ramp up.

Training of the faculty teaching these courses once they were mainstreamed was never what it was in the pilot phase, so there was a loss in the degree to which the new pedagogy was present after the $21 \mathrm{X}$ curriculum was adopted.

One of the issues in obtaining faculty to teach these courses is the teachability of the courses themselves. In the pilot phase the courses were more integrated, requiring ongoing communication among the faculty. In many cases, faculty teaching in the pilots had release time, so they could devote time to meetings with other faculty, something upon which integration of subjects depended. To get the curriculum adopted, some of this integration was lost as the new faculty were not granted release time. Courses became more freestanding. Many of the developers of the original courses were upset and viewed these compromises as watering down the curriculum. They had been exhilarated by the experience of creating and teaching the new 
curriculum over three years and were deeply committed to it. One faculty member at another partner institution referred to the pilot curriculum experience as being in Camelot; now Camelot was being killed. At TAMU, the professor who served as the FC campus coordinator understood the problem:

The pilots were a masterpiece, I agree with that. But at some point you've got to consider economical constraints, administrative constraints. I think I was able to understand the constraints more than the developers. But, on the other hand, it's a lot easier for me to understand the constraints because I wasn't part of the team. They gave their lives! I mean, these people literally gave us three years of their professional lives....I tried to convey to them the compromise, but I think I would have reacted like them if I would have been in their position.

There were people at both ends of this process - developers and reluctant adopters - who were unhappy. It was not an easy time.

Another issue was textbooks. In the 20X pilot phase some faculty wrote textbooks to go with the curriculum, and these were used in the $21 \mathrm{X}$ pilot. This created a problem, as one faculty member described, even during that early period:

Now, those textbooks were continued into the second pilot study. Well, now we have a new set of courses with course material that is reorganized, but we're still using the old textbooks. The original textbook writers are unwilling to rewrite the textbooks because, you know, that's their crowning glory. Therefore, this creates now a new friction between those folks and the new course folks. It has been a real problem. Now we have a set of courses with no textbooks, essentially....[In many of the $21 \mathrm{X}$ courses] we've essentially abandoned the textbook that was written specifically with the framework and the Coalition themes embedded in [them] and we've now regressed back to using standard, off-the-shelf...commercial textbooks. As a result this makes it very difficult for the faculty to step in and say, "Where's the textbook that's got all this new stuff in it?"... That continues to be a problem.

Textbooks are fundamental for any curriculum and by their very nature they inhibit change; a new curriculum requires new textbooks, in some form, and A\&M has yet to address this issue satisfactorily.

The transition must also be understood as a political process. As one person noted: "The major departments generally voted for it. Mechanical did, Civil Engineering did, Electrical did. They all wanted some modifications. They wanted this course substituted [or that one changed] and they had to finally hammer [things] out-it was a political process." It was also one that generated uncertainty. The faculty member who coordinated all FC projects at TAMU wondered if there could be any way around this:

The transition was rough for us, because in the transition a lot of people were saying, 'Is 
this program better than that? Look at this, look at that. These students went through here and they still cannot do that,' because you have this nightmare of students going through all this. We're thinking maybe you shouldn't go through this transition [the pilot curriculum]; you should go straight to the full-scale. But then, how do you do that?

It remains a viable question. However, even if an innovation were somehow mainstreamed immediately, there would still be widespread political jockeying and some institutional dislocation-that part seems inevitable.

It's important to note that the transition involved more than getting students and faculty into this new curricular track. It also means that upper division courses had to be adjusted to fit, since students coming into them would have a somewhat different knowledge base than earlier students. This was part of the intention of the FC leaders, but we heard little about this from our informants at TAMU, with the exception of a couple of department heads. One reported: "We did a major revamp of our own curriculum...and launched it two years ago to be sure that the Coalition design fed into it properly, both in terms of the sequence of the courses as well as in terms of proper fundamental preparation." If the FC curriculum is to have a far-reaching impact on the College, this will have to be done in all departments, and there isn't yet evidence that this is happening.

The issues that TAMU struggled with in this implementation process were common across all the FC programs that used a pilot. When these experiences are considered in terms of what the leaders learned, several things stand out. In designing the pilot program, they focused primarily on creating an innovative and effective curriculum and didn't give sufficient thought to other issues. As we saw earlier in the UMD example, some FC teams failed to recognize that students in the pilot didn't adequately represent the diversity of the student body, nor did it involve faculty who weren't already committed to the new curriculum. They also didn't recognize and plan for the complex logistical problems that arise with implementation. They learned on their feet how to do all these things; had they known some of this beforehand, the transition from pilot to adoption could have been smoother.

Referring back to the initial change model in Figure 1, we can see how both greater understanding of the role of assessment data and the limitations of the pilot curriculum contributed to the evolution to a new model of curricular change. New understanding of the curriculum change process is depicted in the second-generation change model shown in Figure 2.

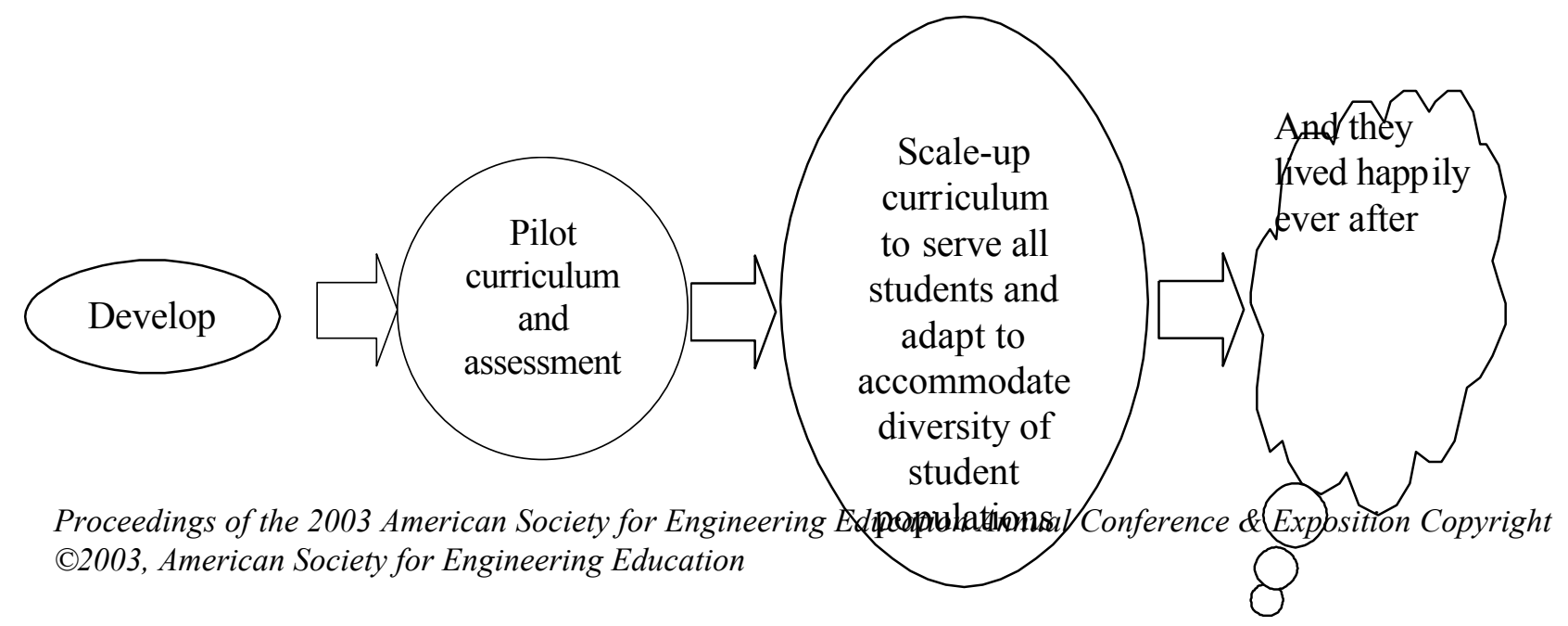


Figure 2. Second-generation Change Model

In the second-generation change model, the emphasis shifts away from pilot curriculum development and assessment, and instead the design of an institutional curriculum system that accommodates all students is given more attention. So the project focus is both on developing a pilot curriculum and carefully assessing student performance as well as attributes that will be useful in designing a curriculum structure for all students. Developers can learn from pilot curricula to see how college-wide curriculum might be designed, but they must use a process that involves all faculty members as well as student advisors to craft a college-wide curriculum. However, the second-generation change model contains two assumptions that further FC experiences demonstrated to be problematic. First, the second-generation change model assumes that existing university and college structures will accommodate the new college-wide curriculum without change. That is, processes such as registration will not need to change and no new college-wide curriculum administrators will be needed. Second, the model assumes that faculty will be able to teach new curriculum with little or no changes and/or development on their part. These assumptions are challenged in the examination of the third issue.

\section{Sustaining the Innovations}

Managing the curriculum in order to sustain the innovations was a critical aspect of institutionalization. There were several challenges FC institutions dealt with.

Unlike traditional curricula, the FC curricula required some kind of oversight in order to maintain their integrity. There needed to be an institutional structure to manage these courses and someone who would facilitate the faculty exchange and planning that maintained course integration. Most importantly, the principles on which the courses were designed needed an institutional "home" that would ensure new faculty were trained and prepared to teach in a new way.

Experiences with Rose Hulman's Sophomore Engineering Core (SEC) provide a good example of how the absence of an institutional structure (and the lack of support for one) was the biggest impediment to full institutionalization. One professor said, "One of the problems that we've had with our sophomore program is that once the development committee went out of existence, there really is no organization that administers [it]. [An FC faculty leader] does it personally." Another professor framed it in terms of ownership:

The engineering science courses are labeled ES... [but] there is no department at Rose which is Engineering Science. The question is, who has responsibility for the curriculum? Right now [the faculty member who] has worked [on this project] for many years, since 1995, when the curriculum was first put in place.... has assumed responsibility for the curriculum.... So you have this question about who owns this curriculum and apparently it's clear that neither of the departments who require it for all of their students think they own it....The dean has responded positively and said, "Yes, I think there needs to be resources allocated to maintain the integrity of the curriculum." But exactly how that will be implemented is yet to be seen. 
The FC campus coordinator agreed, adding:

I've been the team leader for the curriculum since it started, and I've also been the person who has run it since we implemented it. And right now I have on my desk all the schedules for students for next quarter and I have to go balance sections to be sure it works out. And we don't have a structure of anybody else to do that. It's not something that the Mechanical Engineering department head sees as his responsibility, or the Electrical Engineering. And I'm not sure it should be. I believe it should have... somebody whose job it is to try to see across departments. But we've never really set that structure in place. For a couple of years, I actually had a formal Institute position where I had release time to do those things. That's long ago evaporated and I continue to do them, but I'm not sure how that's going to happen when I don't do them.

In addition to the ownership question, there is also the issue of a having a structure in place that provides a framework for ongoing dialogue about the curriculum and a venue for ongoing change. As for the evolution of the curriculum itself, the FC sophomore leader at Rose admits that there is no formal mechanism for making changes and this is a concern:

That's probably one of the things I'm least happy about.... We haven't had a lot of meetings, ongoing structural meetings of maintaining stuff. We tried to the first year...and we also met the very first summer...and we assessed where we had been and had faculty feedback....So the courses have sort of evolved and we've talked to each other, but they've evolved sort of in parallel with each other....But we've never since the start of the curriculum sat down as a team, either that team or a subsequent team, and said, "OK, what do we have? How's it working? What changes need to be made?"....I think it's a problem.

There's also evidence that the curriculum as originally designed has begun to drift somewhat, moving back towards the traditional curriculum. One professor noted, "The coordination between engineering faculty and math faculty is pretty much stopped." The math sequence that had been redesigned for the SEC has been melded with the traditional math sequence, so some of that uniqueness has been lost. There is also much less coordination across the five engineering courses. Those who teach sections of the same course meet at the beginning to discuss the syllabus but then meet only occasionally and briefly during the quarter. Using traditional textbooks, as one faculty member noted, also contributes to drift. He also points out another problem:

In the technical disciplines, it tends to be the research areas that feed the disciplines and keep things current and alive and provide new information and insights. For these lower level [courses], there isn't anybody doing development of an integrated engineering science curriculum that provides input into this process. And without that I'm not sure it can stay together.

That last point is an interesting one. This curriculum seeks to give students an understanding of 
the fundamentals of engineering science, but there is no field of engineering science to support it in an ongoing way. It's another way of arguing that any curriculum needs continuous development if it is to stay vibrant and alive.

The other FC institutions had similar experiences. During the pilot phases an engineering faculty member who acted as coordinator handled daily management of each FC program. At Alabama, the coordinator made sure that FC faculty from math, physics and chemistry met regularly with engineering faculty, and was also available to address any issues students had. This person was responsible for the smooth functioning of the program, and when no one served in this role during the fourth year of the pilot, the program suffered. Now UA has made this an official position and that faculty member has a reduced teaching load to compensate for the administrative duties of the position.

At UMD, an associate dean was assigned the job of overseeing their freshman program, IMPULSE. A budget was created and the college prepared to assume financial responsibility for the program once the FC grant ran out. An administrator told us, "Ultimately you can not simply rely on one giant grant to make an effective, long lasting change in the way you do things. It has to be continued - continuous."

At some campuses, the lack of faculty training contributed to a "drift" back to the way things were. At UMD faculty are being assigned to the new courses with no more preparation than normal. One faculty member commented that faculty members new to the FC courses "need to know that this is a different way of delivering engineering education."

Texas A\&M successfully created a structure to maintain their sophomore curriculum . When that curriculum was adopted, several elements were put in place that structured how the program would function. The curriculum consists of five engineering courses. Each course was assigned to a specific department; in a curricular sense the department "owns" the course and is responsible for its content. A course coordinator from that department is assigned to organize the teaching of the course by the various faculty members who are teaching it that semester. These course coordinators also help prepare new faculty on both the course content and the new pedagogy involved. Many have regular meetings with these faculty; all try to assist with the teaching in any way they can. There is also an overall coordinator who serves as an ombudsman and as a liaison between the course coordinators, the associate dean for academic programs, and the department heads. This person, a senior professor, was chosen by the department heads and the associate dean, both for his support of the program and for his credibility with the faculty. Staffing of these courses is the responsibility of the associate dean who uses an elaborate formula earlier referred to as the barter system. This process allows the College to adjust to the shifting demographics and needs of the various departments.

This management structure at A\&M provides stability to the sophomore program, but it has some costs. Departments choose which of the sophomore FC courses they will require for their students, and they retain the right to drop any of these required courses. They can't make that decision unilaterally-they have to negotiate this with the associate dean-but the program is weakened politically when a department does make this decision. There are also risks to the curriculum itself. Giving responsibility for course content to the departments lessens the control 
of the associate dean over the program and thereby reduces the means available for quality control; much of this depends on the interest and effort expended by the course coordinators. The risk is that the curriculum can be watered down over time. The barter system itself, while insuring that the program will be supported across the College, means that faculty whose training is in different content areas may teach some courses. All of these factors mean that the FC curriculum is always somewhat at risk of being subverted.

With these new insights on the challenges of sustaining curricular innovation, a third change model can be constructed. This "third-generation" change model is depicted in Figure 3. In this model, the project focus has been expanded further. Now, curricular innovation projects will include developing, implementing, and carefully assessing a pilot curriculum for student performance and learning required to design college-wide curriculum. Next, developers will use knowledge gained from pilot curriculum efforts to design a college-wide curriculum system with high faculty and administrative involvement. Finally, the innovation effort will consider developing new administrative structures within the college that will support the new curriculum.

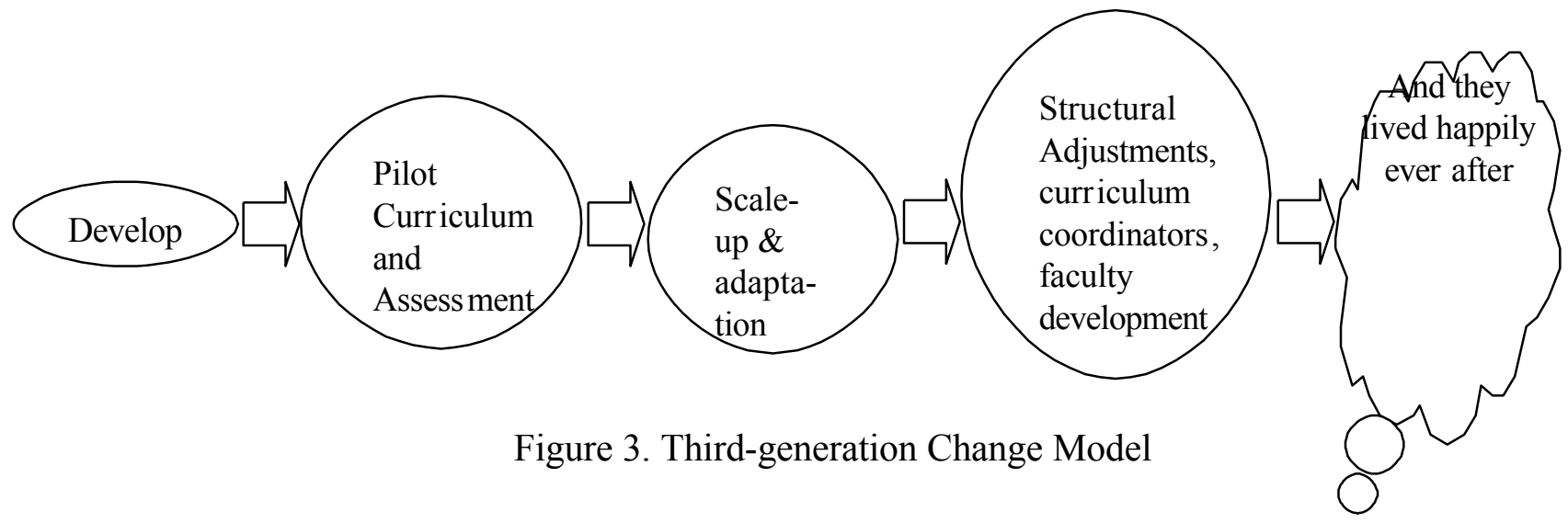

\section{Discussion}

Figure 3. Third-generation Change Model

In our study of the Foundation Coalition, we sought to understand how the FC leaders and the faculty and administrators in their institutions experienced the process of curricular change. It is an enormously complex process. In this paper we have focused on one element of that process, namely how the understandings about change held by the FC leaders evolved as they moved through the process of developing and implementing a new curriculum. The models of change that we have developed here represent how their thinking changed as they experienced the reactions to their initiatives by their colleagues within their institutions. Each institutional context is, of course, unique, but we were able to see some commonalities in the process across institutions. The three issues that we highlight in this paper - the role of assessment data, the limitations of the pilot for gaining full-scale adoption of the new curriculum, and the need for structural change to sustain the new curriculum - are issues that all of the FC programs had to address. We have chosen to focus on these three issues because of their prominence in the process, but they are not the only experiences that shaped both the final outcome and how the leaders understood what they were trying to do; our analysis of our data continues. As we said 
above, curricular change is an enormously complex process and our study will enable us to say much more about it.

What we are arguing here is that the model of change that guided the FC leaders became progressively more complex over time. In the beginning they thought of the change process as analogous to the engineering design process, with the emphasis on developing a prototype (the pilot program), testing it (the assessment data), making the necessary changes based on those data, then putting it forward for adoption (Figure 1). When they discovered that assessment data were not persuasive in and of themselves, and that the pilot didn't give them the kind of experience they needed to make the new curriculum work for all their students, they began to understand that this sort of change required that more attention be paid to the complexities of their student population and to the complex calculation that lies behind adoption of the new curriculum within their departments and colleges (Figure 2). Finally, once the curriculum was adopted at their institutions, they learned that that was not the endpoint and that more work had to be done to sustain the new curriculum, particularly through creating institutional structures that would do that (Figure 3).

Had the FC leaders known in 1993 what they knew by 1998, they would have done things differently. Hindsight, of course, is always extremely instructive - the challenge is to make that learning available to others. That is the goal of this study. The Foundation Coalition has already made a very significant contribution to engineering education. [5,11,18-22] It is our hope that what they learned about how to effect curricular change will be helpful to other engineering programs, and in fact to programs across all disciplines, who seek to make significant changes in their own curricula. Better understanding how their ideas about change shape their experience is one contribution we believe will be helpful in this process.

\section{References}

1. Ricketts, P. C. "Present Favorable and Unfavorable Tendencies in Engineering Education." World's Engineering Congress, Chicago, IL, 1894.

2. Silver, H., and Brennan, J. (1988). "Engineering education: A note on the United States." A Liberal Vocationalism, Methuen, New York, NY, p. 137.

3. Merriam, S. (1998). Qualitative Research and Case Study Applications in Education. Jossey-Bass, San Francisco.

4. Bogdan, R. C, \& Biklen, S. K. (1998). Qualitative Research for Education. Allyn \& Bacon, Boston.

5. Froyd, J., and Rogers, G. (1997) "Evolution and Evaluation of an Integrated, First-Year Curriculum," Proceedings, Frontiers in Education Conference, http://www.foundationcoalition.org/publications/journalpapers/fie97/1102.pdf

6. Glover, C.J., and Erdman, C.A. (1992) "Overview of the Texas A\&M/NSF Engineering Core Curriculum Development," Proceedings, Frontiers in Education Conference, Nashville, Tennessee, 11-14 November 1992, pp. 363-367, http://www-chen.tamu.edu/uesc/fie ovrv.pdf 
7. Glover, Charles J., K. M. Lunsford, and John A. Fleming, "TAMU/NSF Engineering Core Curriculum Course 1: Conservation Principles in En gineering," Proceedings, 1992 Frontiers in Education Conference, Nashville, Tennessee, 11-14 November 1992, pp. 603-608, http://www-chen.tamu.edu/uesc/fie crs1.pdf

8. Pollock, T.C. (1992) “TAMU/NSF Engineering Core Curriculum Course 2: Properties of Matter," Proceedings, Frontiers in Education Conference, Nashville, Tennessee, 11-14 November 1992, pp. 609613, http://www-chen.tamu.edu/uesc/fie crs2.pdf

9. Everett, L.J. (1992) "TAMU/NSF Engineering Core Curriculum Course 3: Understanding Engineering via Conservation," Proceedings, Frontiers in Education Conference, Nashville, Tenn essee, 11-14 November 1992, pp. 614-619, http://www-chen.tamu.edu/uesc/fie_crs3.pdf

10. Glover, C.J., and Jones, H.L. (1992) "TAMU/NSF Engineering Core Curriculum Course 4: Conservation Principles for Continuous Media," Proceedings, Frontiers in Education Conference, Nashville, Tenn essee, 11-14 November 1992 Conference, pp. 620-624, http://www-chen.tamu.edu/uesc/fie crs4.pdf

11. Erdman, Carl A., Charles J. Glover, and V. L. Willson (1992) "Curriculum Change: Acceptance and Dissemination," Proceedings, Frontiers in Education Conference, Nashville, Tennessee, 11-14 November 1992, pp. 368-372

12. Johnson-Laird, P.N. (1983) Mental Models: Towards a Cognitive Science of Language, Inference, and Consciousness. Cambridge: Cambridge University Press; Cambridge, MA: Harvard University Press.

13. Pendergrass, N.A., Kowalczyk, R.E., Dowd, J.P., Laoulache, R.N., Nelles, W., Golen, J.A., and Fowler, E. (2001) "Improving First-Year Engineering Education," Journal of Engineering Education, 90:1, 33-41

14. Pendergrass, N.A., Laoulache, R.N., Fortier, P.J. (2000) "Mainstreaming an Innovative 31-Credit Curriculum for First-Year Engineering Majors," Proceedings of the Frontiers in Education Conference, http://fc1.tamu.edu/documents/pdf/mainstreaming 31-credit_curriculum.pdf

15. Millar, S. B., Kosciuk, S., B, Penberty, D., \& Wright, J. C. (1998). A Novel Strategy for Assessing the Effects of Curriculum Reform on Student Competence. Journal Of Chemisty Education, 75, 986-992.

16. Millar, S. B., Kosciuk, S., Penberthy, D., \& Wright, J. C. (1996). Faculty Assessment of the Effects of a Freshman Chemistry Course. Paper presented at the 1996 Annual ASEE Conference.

17. Froyd, J., Penberthy, D., and Watson, K. (2000) "Good Educational Experiments are not Necessarily Good Change Processes," Proceedings, Frontiers in Education Conference, http://www.foundationcoalition.org/publications/journalpapers/fie2000/1260.pdf

18. Fournier-Bonilla, S.D., Watson, K.L., Malave, C.O., Froyd, J.E., 2001, "Managing Curricula Change in Engineering at Texas A\&M University," International Journal of Engineering Education, 17:3, 222-235.

19. Caso, R., Clark, C., Froyd, J., Kenimer, A., Morgan, J., Rinehart, J. (2002) "A Systemic Change Model in Engineering Education and Its Relevance for Women," Proceedings, ASEE Annual Conference

20. Pendergrass, N.A., Laoulache, R.N., and Fowler, E. (2001) "Can An Integrated First-Year Program Continue To Work As Well After The Novelty Has Worn Off?” Proceedings, ASEE Annual Conference.

21. Richardson, J. and Dantzler, J. (2002) "Effect of a Freshman Engineering Program on Retention and Academic Performance", Proceedings, Frontiers in Education Conference,

22. Richards, D.E., 2001, "Integrating the Mechanical Engineering Core," Proceedings, ASEE Annual Conference.

\section{CAROLYN CLARK}

Carolyn Clark is an associate professor of adult education at Texas A\&M University. She received her doctorate in

Proceedings of the 2003 American Society for Engineering Education Annual Conference \& Exposition Copyright (C2003, American Society for Engineering Education 
adult education from the University of Georgia in 1991. Her research interests include learning and identity development, personal and organizational transformational learning, and narrative as a mode of learning and development. She is a qualitative researcher who teaches and writes on qualitative issues.

\section{JEFF FROYD}

Jeff Froyd is the Director of Academic Development at Texas A\&M University and currently serves as the Project Director for the Foundation Coalition and the NSF Gender Equity Project, Changing Faculty through Learning Communities. His interests include learning, individual and organizational change, and engineering education.

\section{PRUDENCE MERTON}

Prudence Merton is a qualitative researcher and adult educator. Ms. Merton has a Masters of Science degree in Horticulture from Texas A\&M University and is currently working on her dissertation in Adult Education which she plans to complete by May, 2003. Her research interests include occupational narratives, life history research, and teaching/learning in higher education.

\section{JIM RICHARDSON}

Jim Richardson is an associate professor of civil engineering at the University of Alabama in Tuscaloosa. His teaching and research interests include structural analysis and design, especially design and maintenance of highway bridges. He has worked with faculty and researchers at UA and other Foundation Coalition universities since 1994 to develop innovative programs and tools for engineering education. 